\title{
Hydrography and circulation south of Cyprus in late summer 1995 and in spring 1996
}

\author{
George ZODIATIS ${ }^{\text {a }}$, Athanasios THEODOROU ${ }^{\text {b* }}$, Andreas DEMETROPOULOS ${ }^{\text {a }}$ \\ ${ }^{a}$ Laboratory of Physical Oceanography, Department of Fisheries, MANRE, Aeolou 13, 1416 Nicosia, Cyprus \\ ${ }^{b}$ Laboratory of Oceanography, University of Thessaly, Pedion Areos, Volos 383 34, Greece
}

(Received 19/11/96, revised 11/09/97, accepted 12/02/98)

\begin{abstract}
The hydrodynamical characteristics of the area south of Cyprus in the Levantine Sea were examined in late summer 1995 and in spring 1996. Analysis of the CTD data collected, provided a new dynamic picture of the Cyprus Basin and revealed the existence of the Cyprus Basin cyclonic eddy. The latter circulated to the south of Cyprus and exhibited marked seasonality. Production of Levantine Intermediate Water in the area of the latter eddy occurred. Occasionally, between the Cyprus Basin cyclonic eddy and the southern coast of Cyprus a warm current, the Cyprus coastal current appears to intrude from the east. In late summer 1995, the spatial fluctuations of the mid-Mediterranean jet, the main current of the Eastern Mediterranean Sea, caused the splitting of the Cyprus Basin cyclonic eddy, into two smaller cyclonic ones. During spring 1996, however, the Cyprus Basin cyclonic eddy appears as a single large vortex, occupying the greater part of the area south of Cyprus, and flanked to the south by the Cyprus anticyclonic eddy. $\odot$ Elsevier, Paris
\end{abstract}

\section{circulation / Cyprus Basin / eastern Mediterranean / hydrography / Levantine Basin}

Résumé - Hydrologie et circulation au sud de Chypre à la fin de l'été $\mathbf{1 9 9 5}$ et au printemps 1996. Les caractéristiques hydrologiques du bassin Levantin de la mer Méditerranée, examinées à la fin de l'été 1995 et au printemps 1996, révèlent la présence d'un tourbillon cyclonique au caractère saisonnier marqué, au sud de Chypre, dans la région où se forme l'eau Levantine intermédiaire. Le courant côtier de Chypre, chaud et en provenance de l'est, s'intercale parfois entre le tourbillon et l'île. À la fin de l'été 1995, les fluctuations spatiales du courant médio-méditerranéen, principal courant de la Méditerranée orientale, divisent le tourbillon en deux tourbillons cycloniques plus petits. Au printemps 1996, le tourbillon cyclonique du bassin de Chypre se présente comme un unique grand vortex occupant la majeure partie de la région située au sud de l'île et flanqué au sud par le tourbillon anticyclonique de Chypre. (C) Elsevier, Paris

circulation / bassin de Chypre / Méditerranée orientale / hydrologie / bassin Levantin

\section{INTRODUCTION}

The Levantine Basin constitutes the second largest basin in the Mediterranean Sea and communicates with the Aegean Sea via the Eastern Cretan Arc Straits, and with the rest of Mediterranean through the Cretan passage (see inset map in figure 1). The general features of the hydrology and circulation of the Levantine basin have been broadly known for some time (see, inter alia $[3,7,11]$ ). During the last decade and mainly within the framework of P.O.E.M (Physical Oceanugraphy of the Eastern Med- iterranean) a more detailed picture of water mass distribution and circulation has emerged [13, 16]. However, little is known of the area south of Cyprus (figure 1), which delineates our study area. The main features of the bottom topography of the latter are the elevations of Eratoshenes seamount $(700 \mathrm{~m})$ and the Hecateus Ridge $(400 \mathrm{~m})$, and the depressions of Cyprus $(1900 \mathrm{~m})$ and Lattakia $(1500 \mathrm{~m}$ ) basins (figure 1a).

In summer, the surface layer in the Levantine Sea is dominated by the saline (39.30) and warm $\left(>25{ }^{\circ} \mathrm{C}\right.$; [11])

* Correspondence and reprints 

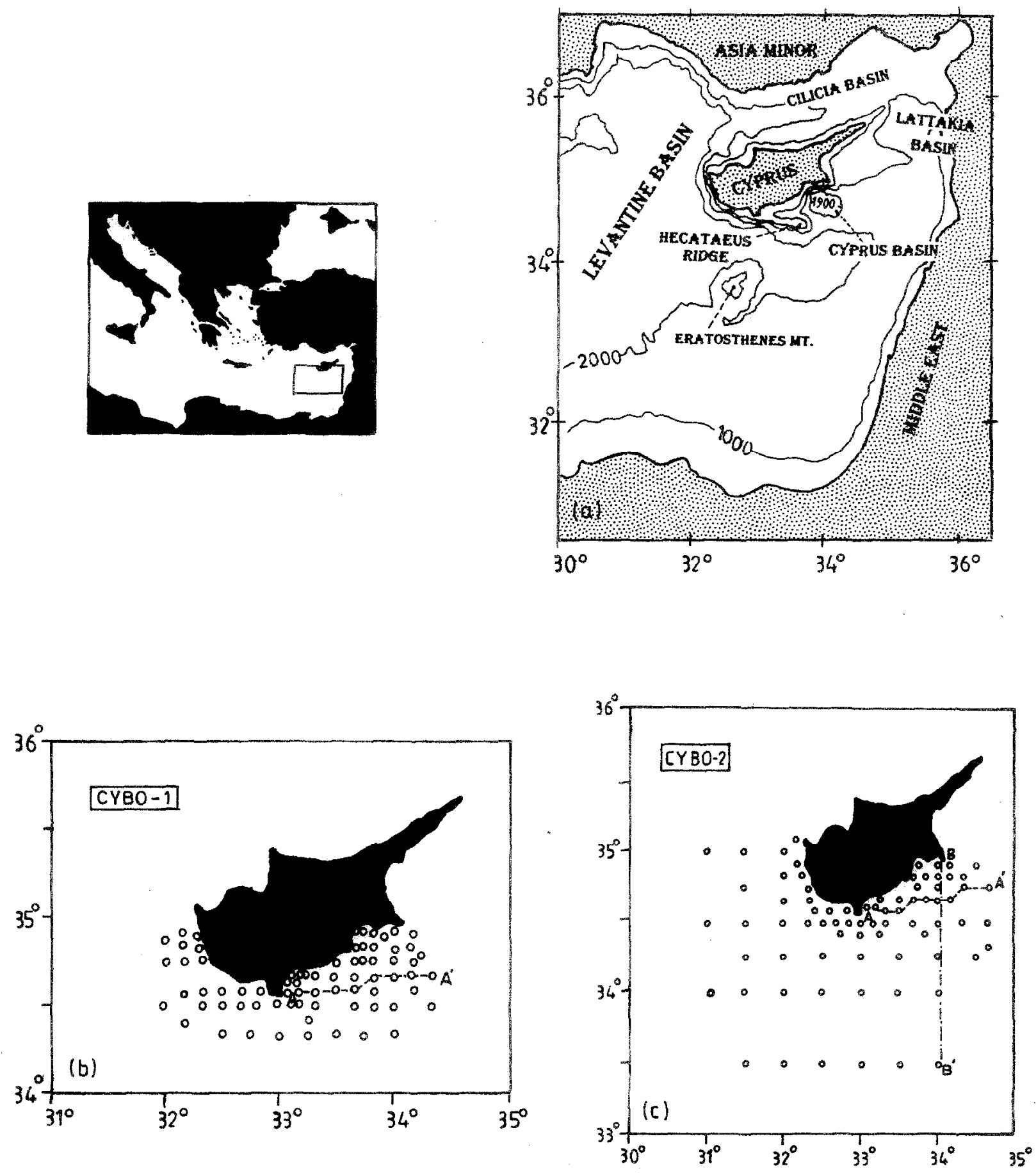

Figure 1. The bottom topography of the Easien Levantine Basin (a). Positions of stations occupied: (b) by M/V Triton during the cruise of September-October 1995, CYBO-1; and, (c) by M/V Sentinel during the cruise of May 1996, CYBO-2. 
Levantine Surface Water (LSW). The latter disappears in winter, whereas it is warmer and saline $\left(19.5^{\circ} \mathrm{C} ; 39.10\right)$ in spring [15]. The LSW spreads westwards from the Levantine Basin and enters the Cretan Sea through the eastern straits of the Cretan Arc, extending northwards as far as the North Aegean Sea, where its interaction with the less saline (32-34) Black Sea Water (BSW) creates a quasi-permanent frontal zone [23, 24]. During cooling metcorological events, the LSW, due to its high-salinity content, becomes denser and sinks to intermediate depths, thereby forming, at various places of the Levantine Sea, the saline Levantine Intermediate Water (LIW) $[1,9,19,25]$. The influence of the latter water mass can be seen throughout the entire Mediterranean Sea at depths between 200 and $600 \mathrm{~m}[20,21,25]$. During its slow westward spreading, the LIW intrudes into the area of the thermohaline dome in the southeastern Ionian Sea and contributes to the formation of a cold and less saline isolated lense at intermediate depths [22]. Between the LSW and the LIW lies the modified Atlantic water (MAW), characterised by a subsurface salinity minimum; the latter, enters the Mediterranean through the Straits of Gibraltar [8], spreading eastward and eventually reaching the present study area. In the deeper layers, waters with the thermohaline characteristics of the Eastern Mediterranean Deep Water (DW) occur [17].

The surface circulation of the Eastern Mediterranean Sea consists of a complicated flow pattern with strong currents and several multi-scaled eddies $[11,13,14,16,18$, 19]. The eastern Levantine Basin is dominated by the sub-basin multilobc cyclonic Rhodos gyre. The latter is flanked to the north by the westward meandering Asia Minor Current (AMC) $[11,13,16]$ and to the south by the mid-Mediterranean jet, which is a continuation of the eastward flowing North African current. The Rhodos gyre extends westwards near Crete in winter, whilst it is restricted eastwards in summer, therehy generating a secondary eddy centre west of Cyprus [12]. Another important feature in the vicinity of the study area is the large scale anticyclonic Shikmona gyre in the south-eastern part of the Levantine Basin, consisting of a number of eddies [13], the northernmost of which, located south of Cyprus at about $34^{\circ} \mathrm{N}$, constitutes the Cyprus eddy [3].

In this paper CTD data, collected within the framework of Cyprus Basin Oceanography (CYBO) Project, are used in conjunction with remote sensing images to describe the water mass circulation in the area south of Cyprus and adjacent regions during late summer 1995 and in spring 1996, and thus contribute to a better understanding of their regional oceanography.

\section{MATERIALS AND METHODS}

During the late summer 1995 cruise, CTD data were acquired on board M/V TRITON on a closely spaced (about $10 \mathrm{~km}$ ) grid of 80 stations in the area south of Cyprus, between 22 September and 16 October 1995 (CYBO-1). A coarser grid was employed in the offshore parts of the study area (figure $1 b$ ). The observations were made using the Sea Bird Electronics (SBE9/11) CTD profiler. The measurements were taken at a rate of 24 scans $\mathrm{s}^{-1}$ and they were averaged in situ over $1 \mathrm{~s}$ intervals. Prior to the cruise, the conductivity and temperature CTD sensors were calibrated at the Sea Bird Metrology Laboratory. To minimize the effects of salinity spikes, the raw data were filtered through a forward and backward low pass filter. An interpolation scheme was used to obtain values at various nominal depths. During the subsequent processing the data were subjected to objective analysis. This mathematical technique for the spatial interpolation of irregularly spaced in situ observations (temperature, salinity, dynamic height) was based on the successive correlation scheme employed by Levitus [6]. This scheme does not differ significantly from the method based on the statistical interpolation with an isotropic homogeneous correlation $[3,5]$. The maps of the geostrophic current vectors have been constructed by the employment of the dynamic method using $750 \mathrm{~m}$ as a reference level, which is considered reasonable for the area under study. A modified Helland-Hansen-Somov method [2] has been used to extrapolate the dynamic heights at shallower stations. This method assumes an infinitely deep sea of quiescent water below the surface layer.

During the spring 1996 cruise, the CTD data were acquired on board of M/V SENTINEL on a closelyspaced grid of 80 stations, between 6 and 13 May 1996. This grid, however, covered a broader area than that of CYBO-1, (figure $1 b$ ). All other procedures regarding sampling, salinity despiking, data interpolation and analysis were similar to those of CYBO-1.

Remote sensing satellite data corresponding to the two sampling periods were acquired from the Royal Netherlands Meteorological Institute NOAA-AVHRR receiving station. The composite images (night time and early morning passes) cover the most part of the Eastern Mediterranean Sea. After the initial data processing, the split 
window technique was applied to the data in order to define the actual SST.

\section{RESULTS}

\subsection{Late Summer 1995}

\subsubsection{Hydrology}

The potential temperature and salinity profiles for selected stations (figure 2) show the occurrence of an upper mixed layer (20-30 $\mathrm{m}$ depth), with extremely high salinity (39.4-39.55) and high temperature values (24$26.5^{\circ} \mathrm{C}$ ), due to intense surface heating and evaporation. The surface distribution of the hydrological characteristics (figures $3 a, 3 b$ ) exhibit considerable spatial gradients, with thermohaline changes of about $2^{\circ} \mathrm{C}$ and 0.15 per
$20 \mathrm{~km}$, presumably indicative of strong advective activity. Moreover, two surface waters with characteristics corresponding to those of LSW are evident (figures $3 a, 3 b$ ): in the northeastern part of the study area, warm (25$26.5^{\circ} \mathrm{C}$ ) and saline $(39.5-39.55)$ water presumably originating from Lattakia Basin occurs. Support for the last statement is provided by figure 2 in Ovchinnikov and Foyad [10], also by figure 6a in Oszoy et al. [15], and, moreover, by our figure 4 . The former two figures clearly show that the northeastern part of our study area receives warm and saline waters from the Lattakia Basin rather than from the coastal area of Lebanon. Furthermore, in the latter region the flow is southward due to the influence of the Shikmona gyre. In the southwestern part of the study area, cooler $\left(22.8-23.4^{\circ} \mathrm{C}\right)$ end relatively less saline water (39.36-39.42), most likely associated with the summertime eastward extension of the Rhodos gyre exists. Support for the last statement is provided by the

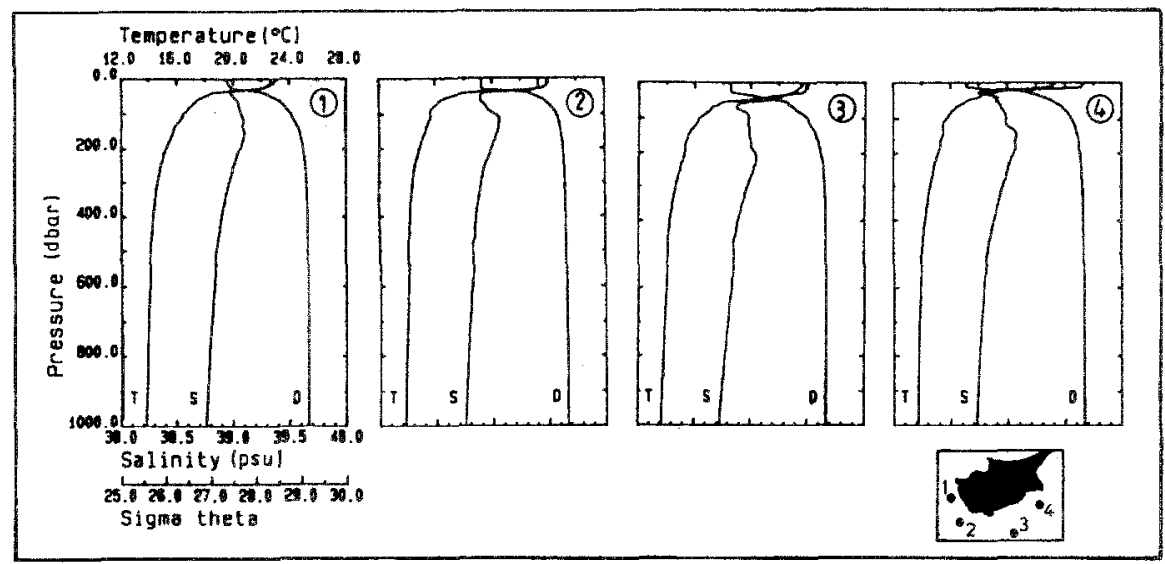

Figure 2. Selected profiles of temperature, salinity and density $\left(\sigma_{\theta}\right)$, in summer 1995, CYBO-1 cruise.
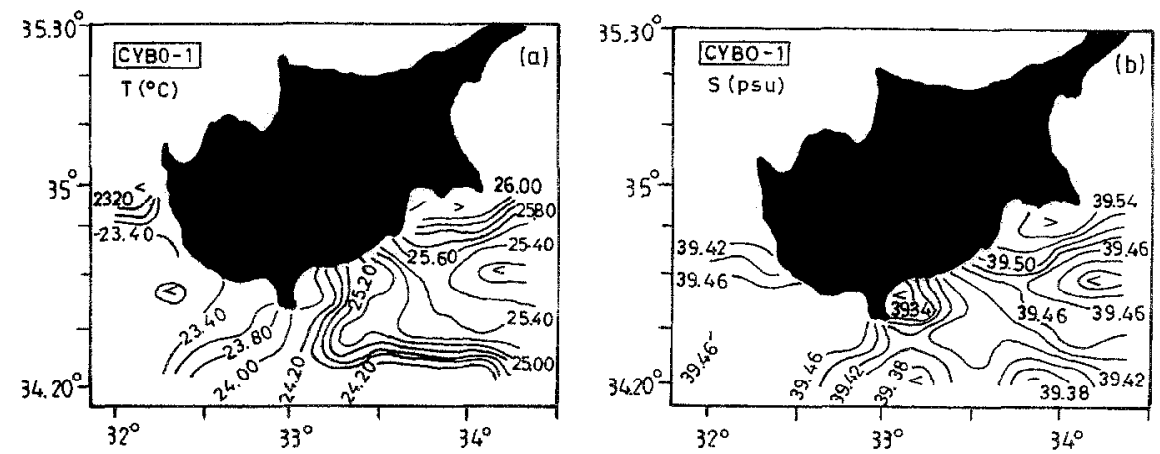

Figure 3. Surface (2 m) distribution of temperature (a) and salinity (b), in summer 1995, CYBO-1 cruise. 


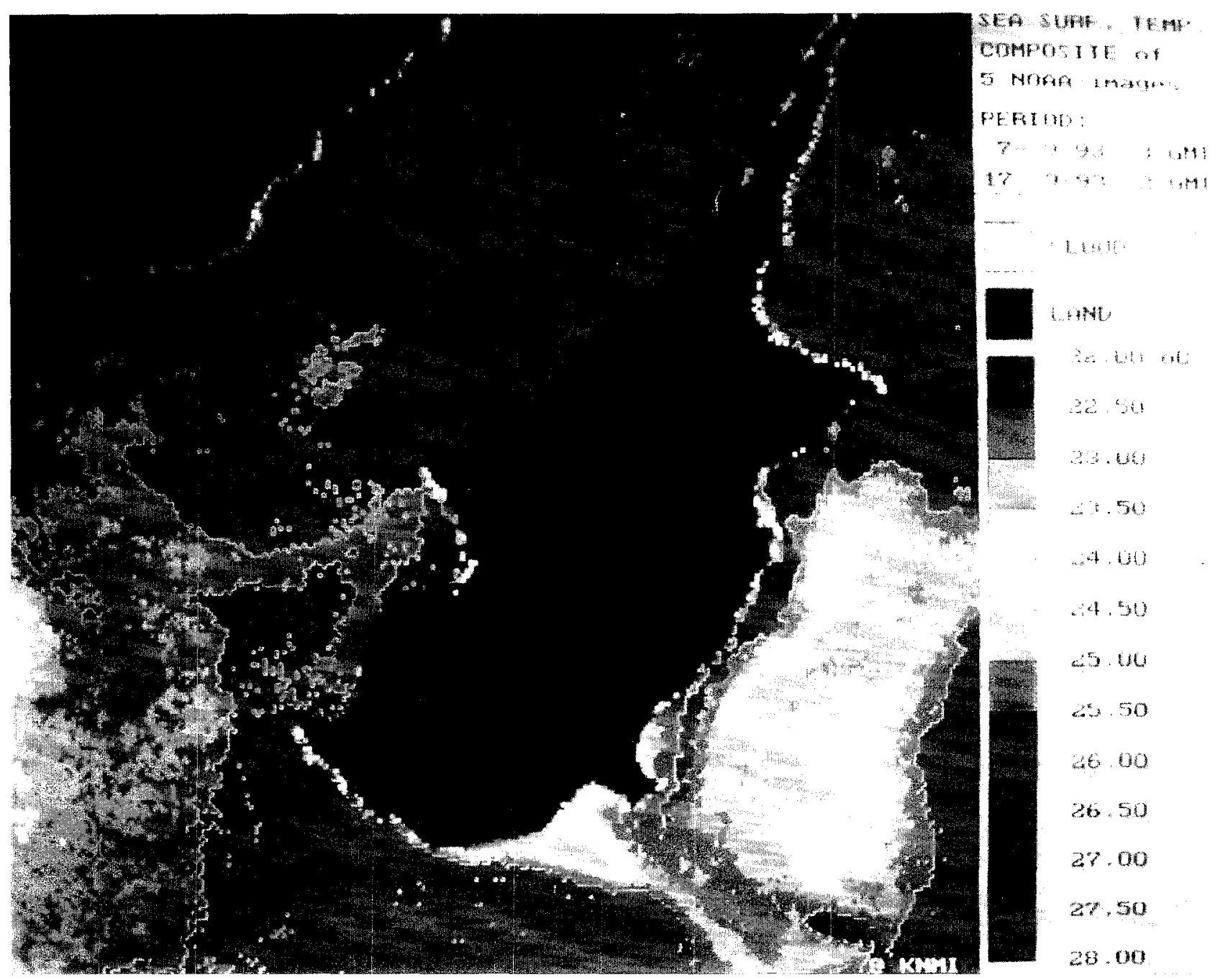

Figure 4. Satellite infrared image of the Hecateus Ridge and Cyprus Basin: weekly composite for late September 1993.

infrared image corresponding to the cruise. A sharp thermal front is evident (figure $3 a$ ) due to the encounter of these two surface waters. To the north of Heacaleus Ridge, less saline and relatively cool water is surrounded by more saline and relatively warmcr waters (figures $3 a$, $3 b$ ), thereby indicating cyclonic activity. A similar feature is also evident in the area of Cyprus Basin depression, indicating the occurrence of the Cyprus Basin cyclonic eddy.

Figure 5 presents the composite $\theta-S$ diagram of all the stations and clearly demonstrates the presence of the following indiginous and in transit water masses: (i) Levantine Surface Water (LSW) of high salinity (39.50-39.55), (ii) subsurface Modified Atlantic Water of low salinity
(38.65), (iii) subsurface Levantine Intermediate Water (LIW) of maximum salinity (39.15), (iv) Deep Water (DW) of low salinity (38.7).

The salinity distribution along the transect AA' (figure 1b) shows (figure $6 a$ ) a marked summer halocline $(0.4$ salinity difference over $15 \mathrm{~m}$ ) between the surface layer and the MAW. Moreover, the finer-scaled vertical salinity section shows (figure $6 b$ ) that MAW and LIW are advected in the form of patches. The summer strong stratification minimised the mixing and the consequent modification of the thermohaline characteristics of the MAW, whose core (38.68-38.75) occurs at depths of 40 to $80 \mathrm{~m}$. At depths of 100 to $200 \mathrm{~m}$ a salinity maximum (39.1) identifies the core of the LIW, whilst the DW occurs deeper. 


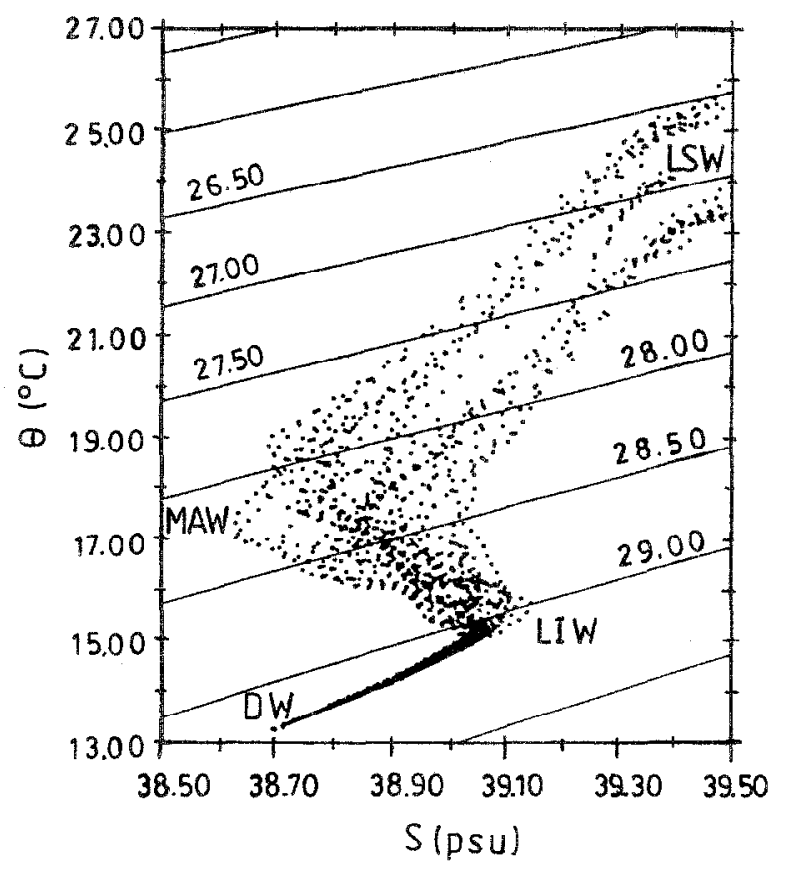

Figure 5. Potential temperature $(\Theta)$ and salinity (S) relationships for all stations in summer 1995, CYBO-1 cruise.

\subsubsection{Circulation}

The summer surface circulation pattern reveals (figure 7a) the presence of: (i) two cyclonic eddies, one to the north of Hecateus Ridge, and another in the Cyprus Basin, confirming their inferrence above; (ii) the midMediterranean jet, which dominates in the southernmost part of the study area, and (iii) the Cyprus Coastal current, which flows westward to the north of the Cyprus Basin cyclonic eddy. The latter flow transfers warm and saline waters from Lattakia Basin along the southern coastline of Cyprus.

The high rates of net water loss due to evaporation from the Levantine Basin is balanced by the water inflow of the mid-Mediterranean jet. The latter exhibited during CYBO-1 average speeds between $20-25 \mathrm{~cm} \cdot \mathrm{s}^{-1}$ and reached a maximum speed of $40 \mathrm{~cm} \cdot \mathrm{s}^{-1}$. The eastward meandering movement of the mid-Mediterranean jet transfers subsurface MAW and LIW from the western Levantine basin to the study area. To the southwest of Cyprus, a relatively weak branch of the mid-Mediterranean jet bifurcates northwards, subsequently turning to the northwest along the southwestern coast of Cyprus
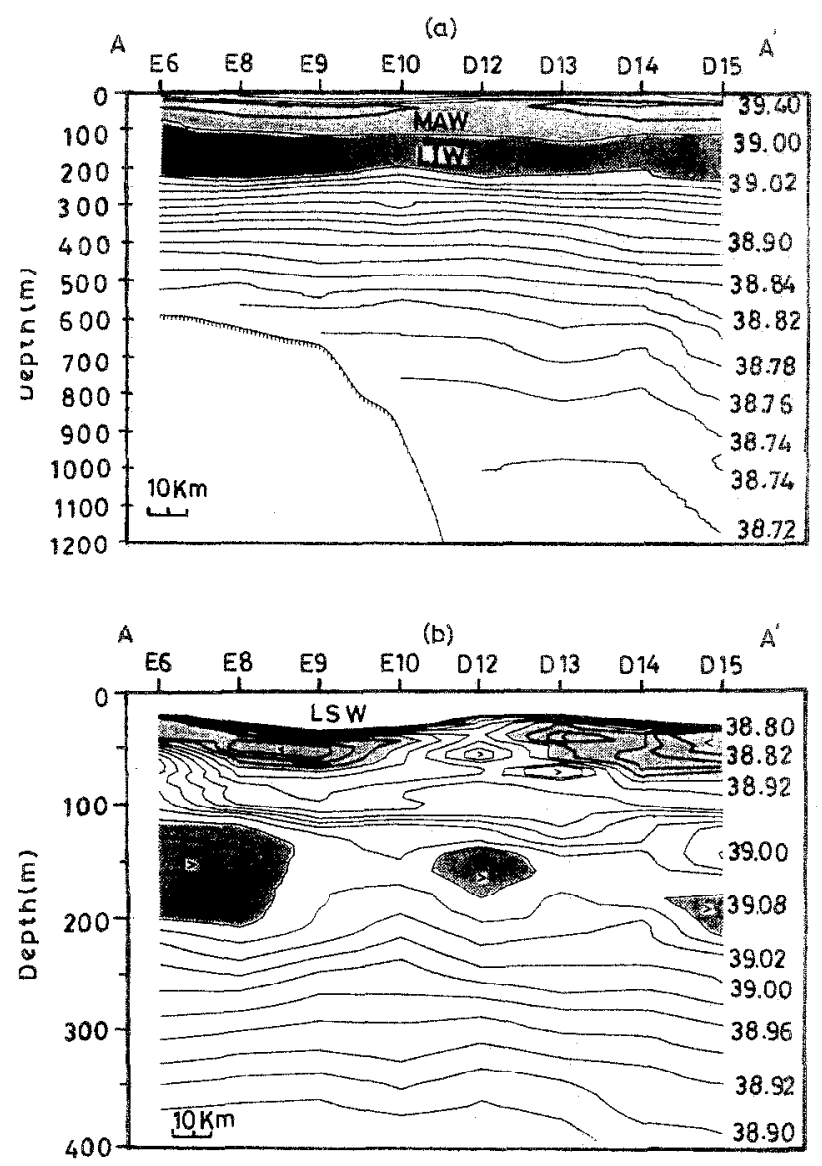

Figure 6. Salinity east-west section $\mathrm{AA}^{\prime}$ (see Fig. 1b) for CYBO-1 survey. (h) Fine vertical salinity distribution for the upper part of (a).

(figure 7a). This latter flow encircles the eastern periphery of the Rhodos gyre.

The Cyprus Basin cyclonic eddy appears to be generated by the interaction between the opposing flows of midMediterranean jet and the Cyprus Coastal current. In contrast, the bifurcation of the mid-Medilerranean jet to the southwest of the Hecataeus Ridge is possibly due to horizontal baroclinic instability, whilst the effect of the morphology of the area seems to be responsible for the formation of the Hecataeus cyclonic eddy activity.

At intermediate depths (50 and $100 \mathrm{~m}$ ) the flow patterns appear to be weakened $\left(<5 \mathrm{~cm} \cdot \mathrm{s}^{-1}\right)$ when compared to that of the surface (figures $7 b, 7 c$ ). Moreover, the northward bifurcation of the mid-Mediterranean jet southwest of Cyprus is restricted to the upper $50 \mathrm{~m}$ layer (figure $7 \mathrm{~b}$ ). Below this level the mid-Mediterranean jet retains its eastward flow without any deflection (figure $7 c$ ). Also, at 


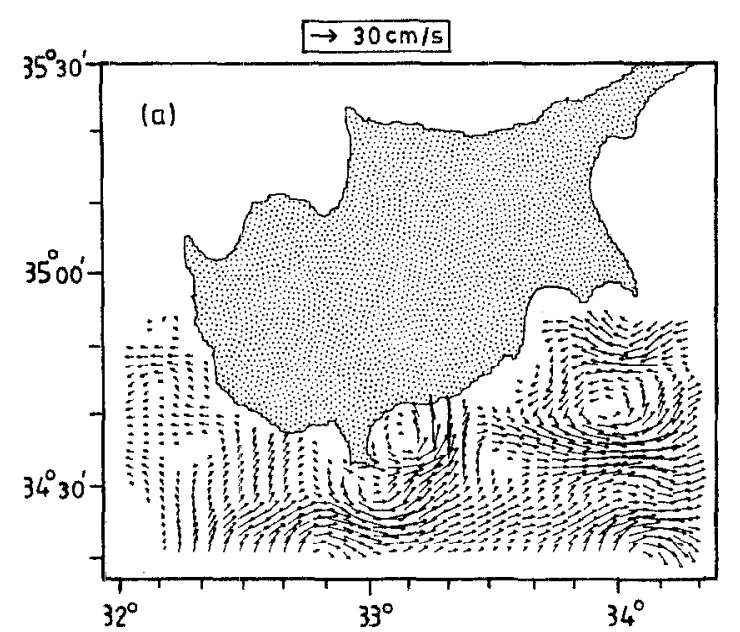

(a)

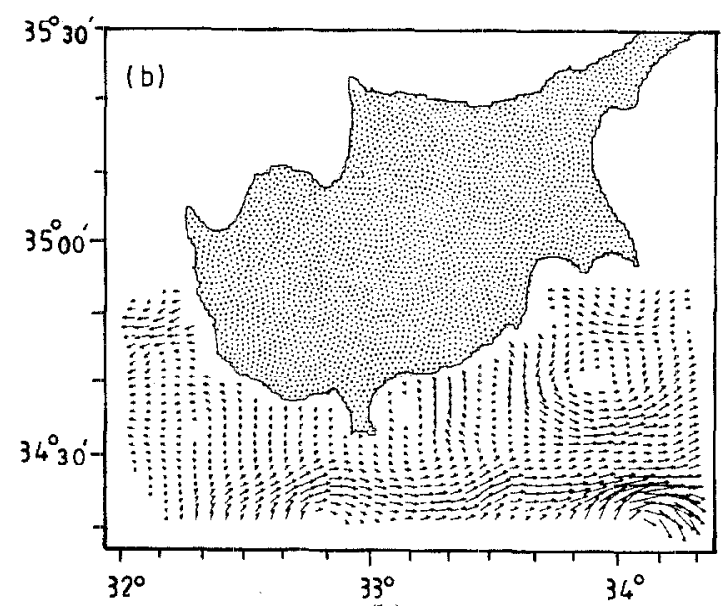

(b)

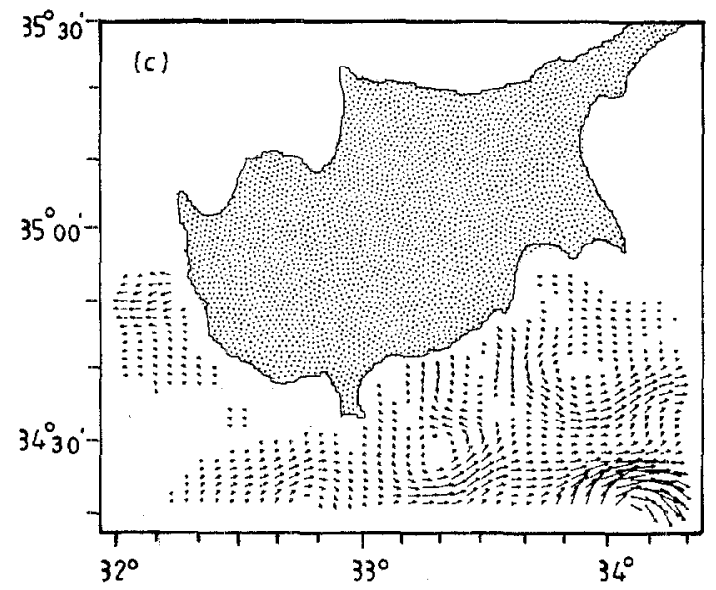

(c)

Figure 7. The geostrophic velocity structure at (a) $2 \mathrm{~m}$, (b) $50 \mathrm{~m}$, and (c) $100 \mathrm{~m}$, in units of $\mathrm{cm} \mathrm{s}^{-1}$, for summer 1995, CYBO-1 cruise. A reference arrow is shown at the top. the latter level, a shift of the Hecataeus cyclonic eddy to the south, and the presence between the two cyclonic eddies of a small-scale anticyclonic eddy are evident (figure $7 c$ ). The latter figure demonstrates also the advection of the LIW by the mid-Mediterranean jet into the study area.

\subsection{Spring 1996}

\subsubsection{Hydrology}

The composite $\boldsymbol{\theta}$-S diagram, based on all spring data collected (figure 8), reveals the presence of the same four water masses: LSW, MAW, LIW and DW, identified in summer 1995. However, during this period, the MAW is hardly discernible as a subsurface salinity minimum, presumably due to mixing processes. Figure 8 also shows the formation of a seasonal thermocline in the uppermost 10 $20 \mathrm{~m}$ layer, while it stresses the importance of the temperature gradient in the stratification of the surface waters.

The horizontal surface distribution of the thermohaline characteristics (figure 9 ) indicates the occurrence of a relatively low salinity water (38.94-39.00) extending from the southwestern part of the study area and intruding into

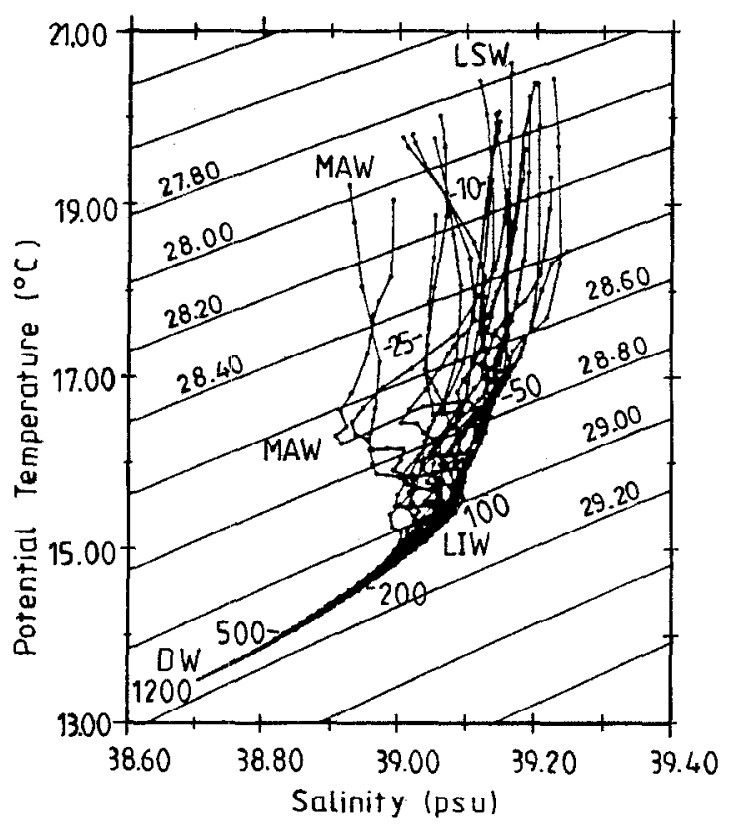

Figure 8. Potential temperature $(\Theta)$ and salinity (S) relationships for all stations in spring 1996, CYBO-2 cruise. 

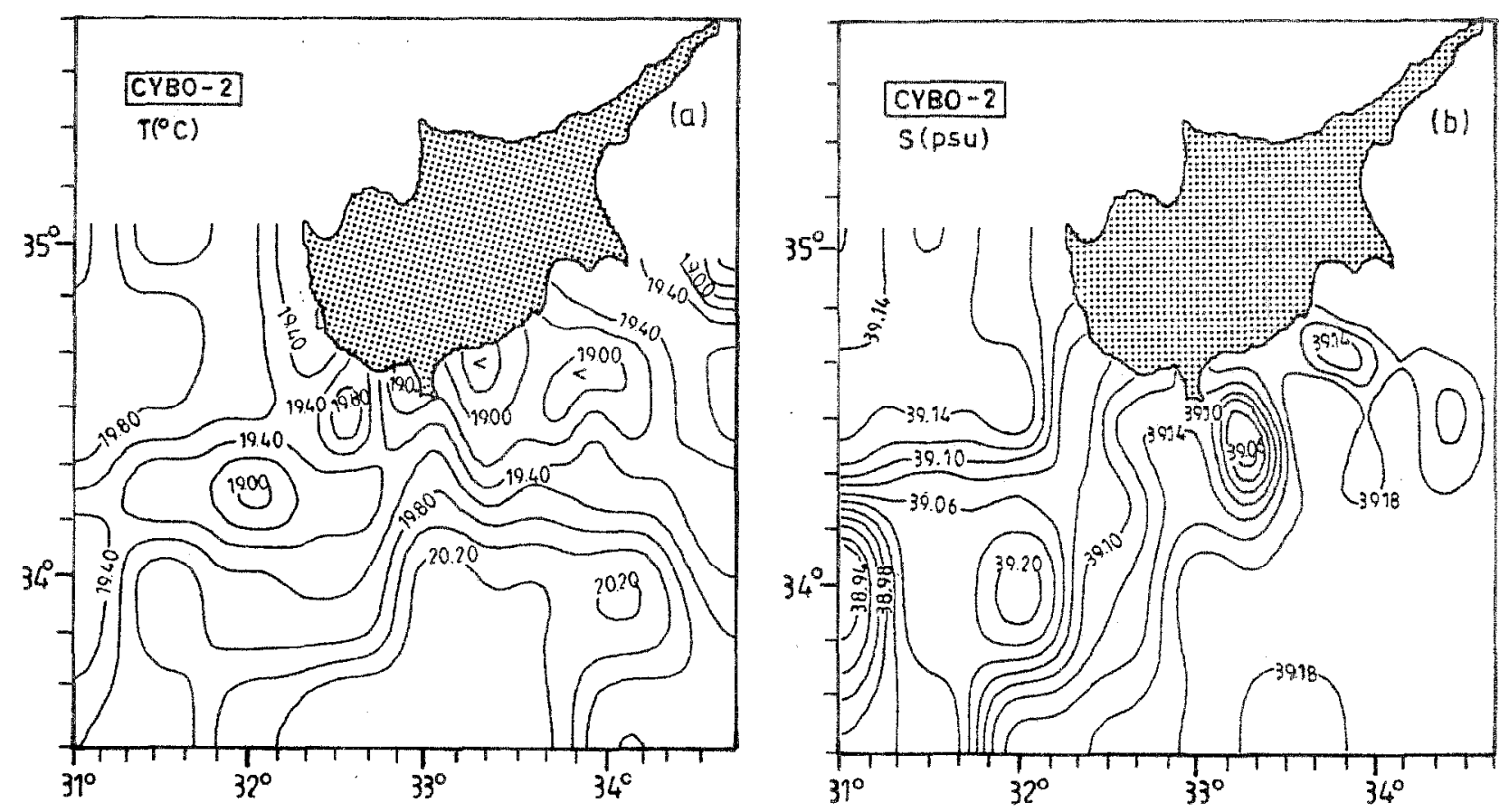

Figure 9. Surface $(5 \mathrm{~m}$ ) distribution of temperature (a) and salinity (b), in spring 1996, CYBO-2 cruise.

the Cyprus coastal waters (figure 9b); this low salinity watcr is flanked to the southcast by an arca of high salinity (39.18-39.20) waters in the vicinity of the Cyprus anticyclonic eddy. The latter constitutes the northernmost anticyclonic eddy of the Shikmona gyre system. The northern part of the study area is covered by cool and less saline water, whilst relatively warm and saline water occurs in the southern part. Moreover, small scale patches consisting of relatively less saline water (39.02-39.06) occur (figure $9 b$ ), presumably associated with the meandering flow of the mid-Mediterranean jet. Although the horizontal thermal gradients are generally small (figure 9a), some features clearly stand out. Thus, in the northeastern part of the study area, in the vicinity of Lattakia Basin, cold surface water $\left(18.6-19^{\circ} \mathrm{C}\right)$ occurs, presumably associated with the cyclonic eddy reported by Oszoy et al. [13]. Also, another cool $\left(18.9-19.2{ }^{\circ} \mathrm{C}\right)$ and relatively less saline (39.02-39.04) water is evident in the area of the Cyprus Basin, which presumably surfaces due to the cyclonic eddy activity in the Cyprus Basin.

Both the zonal (AA') and the meridional (BB') sections (see figure $1 b$ ) indicate (figures 10,11 ) that last winter intense mixing processes occurred in the area of Cyprus
Basin cyclonic eddy. Cooling and wind induced evaporation contributed to the increase of the surface water density sufficiently to overturn the water column. The hydrological characteristics across the section AA' which intersects the centre of the Cyprus Basin cyclonic eddy-, shows (figure 10) a thermohaline dome with wellmixed waters down to 180 to $200 \mathrm{~m}$. Figure $10 \mathrm{~b}$ vividly demonstrates that convective mixing processes occurring between stations D11 and D13 extended down to about $200 \mathrm{~m}$. Also figure $11 \mathrm{~b}$ shows the presence of an almost homogeneous thermohaline dome, flanked by strongly inclined isolines, which indicate the influence of the Shikmona gyre. The combination of the anticyclonic eddy activity with the thermohaline dome (corresponding to the Cyprus basin cyclonic eddy contributes to the sinking of the waters formed in the area of the latter to depths of about $400 \mathrm{~m}$. The meridional salinity section BB' -also intersecting the centre of the Cyprus Basin cyclonic eddy - shows (figure 11) the 39.08 isohaline reaching the surface to the north (in the eddy centre) and descending to about $400-450 \mathrm{~m}$ in the south. Both these salinity sections vividly demonstrate the mixing and sinking mechanisms in the Cyprus Basin. Thus, it seems that dense water formed in the Cyprus Basin cyclonic eddy, 

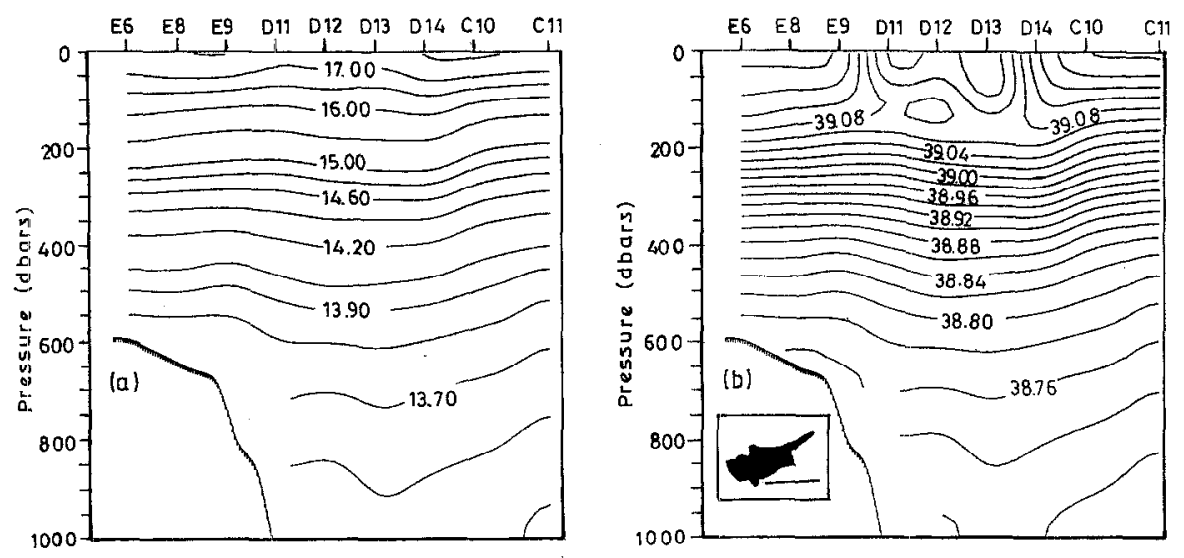

Figure 10. Zonal temperature (a) and salinity (b) sections (AA' in Fig. 1c) across the Cyprus Basin cyclonic eddy in spring 1996, CYBO-2 cruise.

initially sinks down to intermediate depths of about $200 \mathrm{~m}$, thereby forming a water mass with the characteristics of LIW. The latter, in conjunction with the nearby anticyclonic Cyprus eddy, sinks to even deeper depths (400-450 m) (figure 11), spreading subsequently across the southeastern Levantine Basin. The primary cause for both the mixing processes and the formation of L.IW in our study area, was the cooling effect of the previous winter. The above descriptions concerning the mixing and sinking processes were similar to those reported for the Rhodos gyre [1, 4, 19]

\subsubsection{Circulation}

The geostrophic velocity shows (figure 12) that in the spring 1996, the dominant feature was the Cyprus Basin cyclonic eddy, which affected the greater part of the area

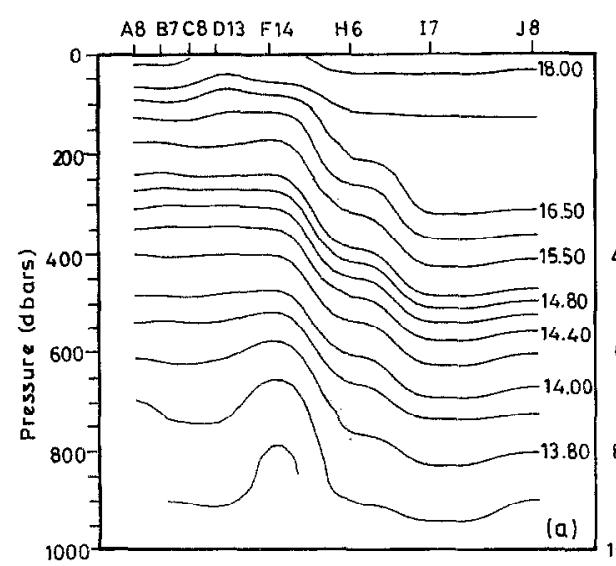

south of Cyprus. The spatial characteristics of this cyclonic eddy when compared to those of late summer 1995, exhibit significant seasonal variations in shape, size and intensity. These changes are primarily linked to the seasonal fluctuations of the mid-Mediterranean jet, and secondarily to the intense mixing processes occurring in its centre. The horizontal extent of the eddy centre is of the order of $50 \mathrm{~km}$, which is almost twice as large as that of late summer 1995. The estimated velocities are rather weak $\left(8-12 \mathrm{~cm} \cdot \mathrm{s}^{-1}\right)$ relative to the surrounding flow activities; however, the eddy was traced down to a depth of $200 \mathrm{~m}$.

The circulation in late summer 1995, was characterised by the bifurcation of the mid-Mediterranean jet, which caused the split of the large Cyprus Basin cyclonic eddy in two, thereby forming the semi-permanent Hecataeus

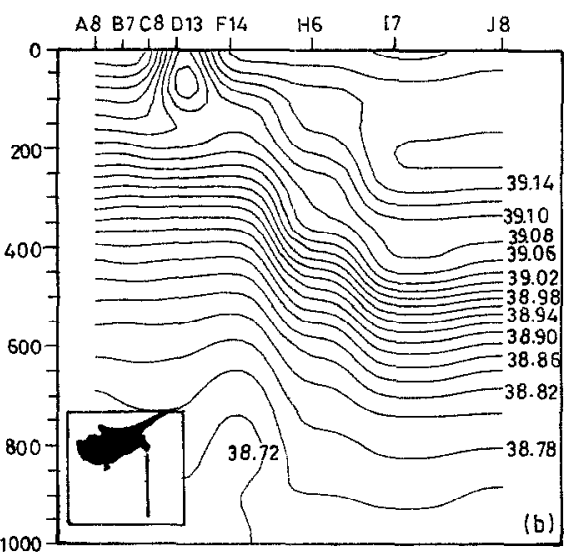

Figure 11. Meridional temperature (a) and salinity (b) sections (BB' in Fig. 1c) across the Cyprus Basin cyclonic eddy in spring 1996, CYBO2 cruise. 


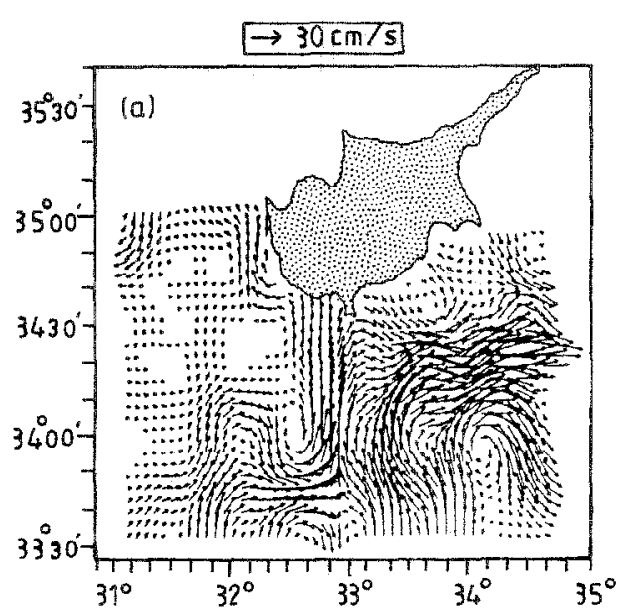

(a)

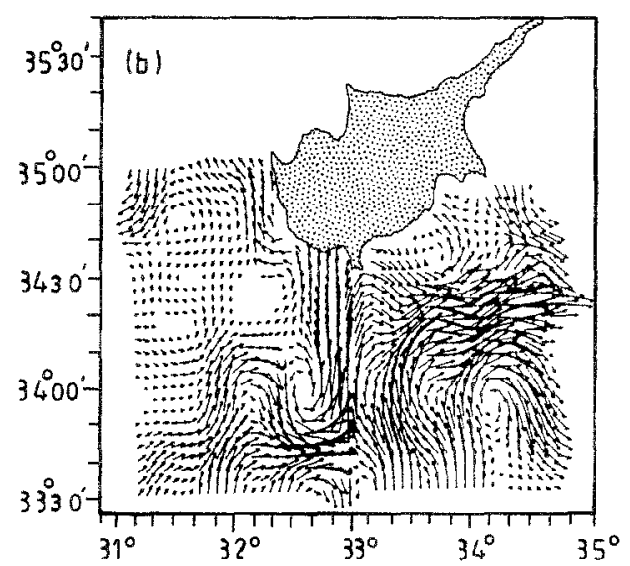

(b)

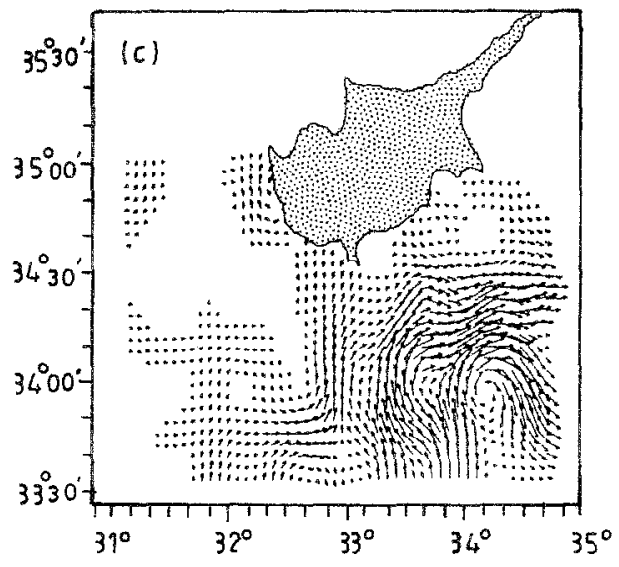

(c)

Figure 12. The geostrophic velocity structure at (a) $5 \mathrm{~m}$, (b) $50 \mathrm{~m}$, and (c) $100 \mathrm{~m}$, in units of $\mathrm{cm} \mathrm{s}^{1}$, for spring 1996, CYBO-2 cruise. A reference arrow is shown at the top. vortex in the Akrotiri Bay. In spring 1996, however, the main axis of the mid-Mediterranean jet was shifted by about 45 to $55 \mathrm{~km}$ to the south, allowing more space for the Cyprus cyclonic eddy to develop as a single entity (figure 12a).

The bottom constraint of the Eratosthenes seamount caused the deflection to the north of the mid-Mediterranean jet. The deflected flow with velocities as high as $28-$ $35 \mathrm{~cm} \cdot \mathrm{s}^{-1}$, is directed towards the southwest coast of Cyprus, where it bifurcates in northwest and eastern directions (figure 12a). The former branch flows along the southwestern and western coast of Cyprus, veering at a latitude of $35^{\circ} \mathrm{N}$ to the west, thereby encircling the easternmost extension of the Rhodos gyre. The main flow of the mid-Mediterranean jet, continues, after bifurcation, to meander eastward between the Cyprus Basin cyclonic eddy and the northernmost anticyclonic eddy of the Shikmona gyre. In Akrotiri Bay, where the Hecataeus vortex was located in late summer 1995 (figure 7), the strong $\left(15-20 \mathrm{~cm} \cdot \mathrm{s}^{-1}\right)$ southeastward current direction presumably reflects the main flow of the mid-Mediterranean jet.

The easternmost extension of the Rhodos gyre can be seen (figure 12a) to the west of Cyprus, as a large scale but weak cyclonic activity. To the north of the latter, an intensification of the current occurs, duc to the interaction of the Asia Minor Current with the detached westward branch of the mid-Mediterranean jet. Similar, although weakened, dynamic conditions prevailed in this area in late summer 1995 (figure $7 a$ ).

In the southeastern part of the study area, and to the south of the meandering mid-Mediterranean jet occurs the Cyprus anticyclonic eddy, which is the northernmost warm core eddy of the Shikmona gyre. The Cyprus anticyclonic eddy, whose influence extends to depths of about $400 \mathrm{~m}$, constitutes the most intense $\left(30-35 \mathrm{~cm} \cdot \mathrm{s}^{-1}\right)$ and dominant dynamic feature in spring 1996. Moreover, this eddy plays a significant role in the formation and spreading of the LIW generated in the area south of the Cyprus Basin cyclonic eddy.

The subsurface (figure 12b) and intermediate (figure 12c) circulation patterns are buth similar to that of the surface, with two exceptions: west of Cyprus and also in the area of the Cyprus Basin cyclonic cddy the flows are somewhat weaker; whereas between the Cyprus Basin cyclonic eddy and the Cyprus anticyclonic eddy the opposite holds.

An interesting feature of the spring 1996 circulation (figure 12) was the absence of the Cyprus Coastal Cur- 
rent. It was well developed in late summer 1995 (figure 7), and its disappearance is presumably due to the marked seasonality of the general circulation. Specifically, in spring 1996, no intrusion of the western part of the Lattakia cyclonic eddy in the area southeast of Cyprus took place. Hence, the Cyprus Coastal Current appears to be a semi-permanent local flow feature. Indeed, this current was identified only in the summer NOAA-AVHRR thermal images.

\section{CONCLUSIONS}

By combining the above results we show in figure 13 schematic qualitative circulation patterns for the two periods. An important finding is the occurrence of the Cyprus Basin cyclonic eddy circulating in the southeastern areas of Cyprus and in the Hecataeus Ridge. The eddy centre was identified as a well developed thermohaline dome, due to the cooling and mixing processes of last winter. The latter oceanographic phenomenology contributes to the sinking of dense water, formed at the surface of the eddy, along the isopycnals down to 400-500 $\mathrm{m}$, thereby leading to local LIW formation. Another important dynamic feature in the area southwestward of Cyprus is the meandering eastward mid-Mediterranean jet. It bifurcates to the northwest in spring 1996, whilst in summer 1995 a double bifurcation was observed. The main flow of this jet streams eastward between the Cyprus Basin cyclonic eddy and the Cyprus anticyclonic eddy. The signal of the mid-Mediterranean jet appears to be stronger during the spring of 1996 than in summer 1995, extending down to twice as deep, to about $200 \mathrm{~m}$. The bifurcated branch of this current flows along the western boundary of Cyprus. The westward flow along the southeast boundary of Cyprus, the Cyprus Coastal Current emerged as a significant feature of the local circulation in summer 1995, nevertheless, it was absent in spring 1996.

\section{Acknowledgments}

The data were collected within the framework of the Cyprus Basin Oceanography programme (CYBO) funded by the Government of Cyprus. Thanks are due to anonymous reviewers for their pertinent comments. The authors would like to thank J. Chrysanthou, H. Yiannoullos, M. Zavros for their cooperation in the realization of the two cruises. Special thanks are due to Mrs Bella Theodorou for technical assistance with the figures.
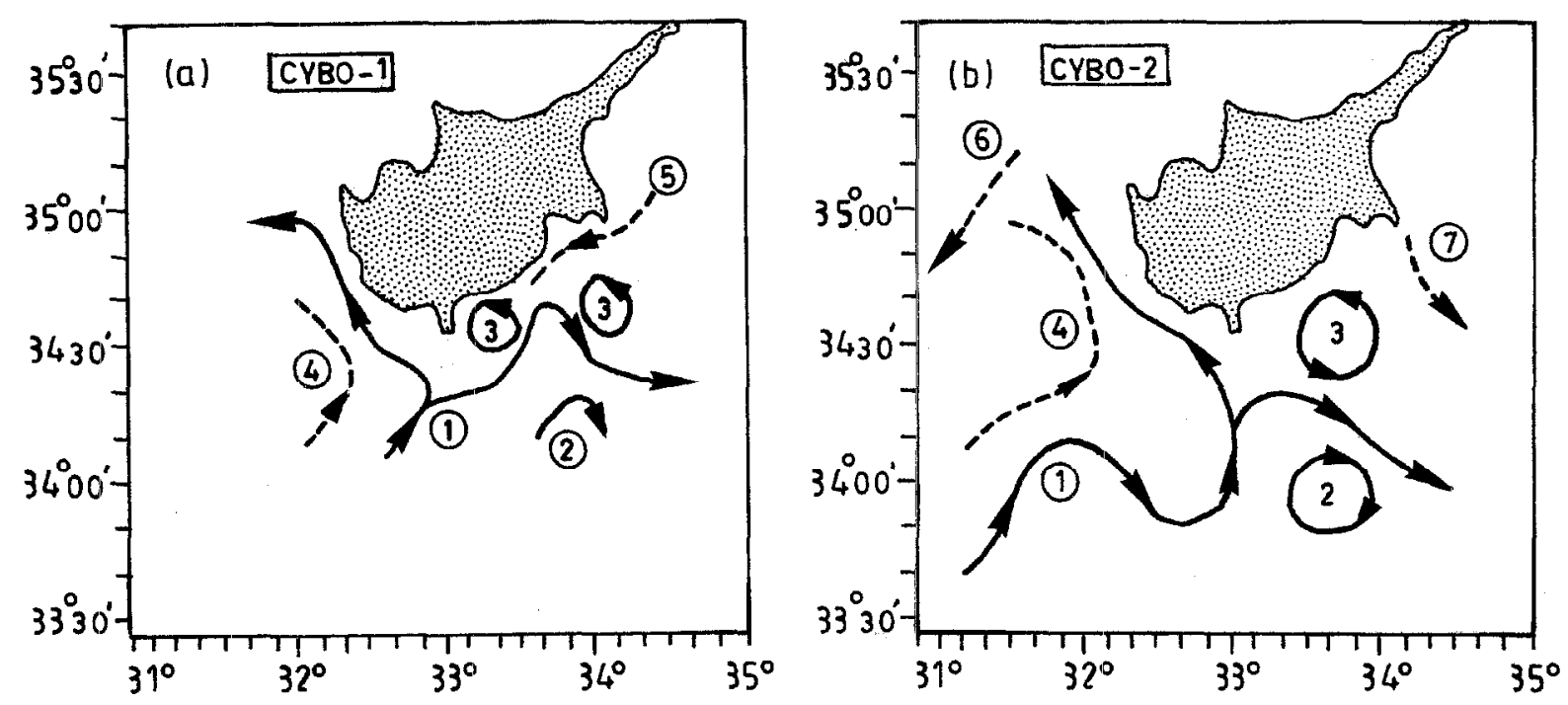

Figure 13. Schematic representation of the circulation patterns: (a) in summer 1995, CYBO-1, and (b) in spring 1996, CYBO-2. (1): midLevantine jet; (2): Cyprus anticyclonic eddy; (3): Cyprus Basin cyclonic eddy; (4): eastern extension of Rhodos gyre; (5): Cyprus Coastal Current; (6): branch of Asia Minor Current; (7): south-westward extension of Lattakia Basin cyclonic eddy. 


\section{REFERENCES}

[1] Anati D.A., A Dome of Cold Water in the Levantine Basin, Deep-Sea Res. 3110 (1984) 1251-1257.

[2] Bourkov V.A., Moroshkin K.V., The reduction of dynamic heights to uniform level, Oceanology 5 (1965) 548-553.

[3] Brenner S., Structure and Evolution of Warm Core Eddies in the Eastern Mediterranean Levantine Basin, J. Geophys. Res. 94 (1989) 12593-12602.

[4] Gertman I.F., Ovchnnikov I.M., Popov Y.I., Deep convection in the Eastern Basin of the Mediterranean Sea, Oceanology 34, 1 (1994) 25-31.

[5] Grillaki-Steiert D., Amoroso V., Analysis Systems for the Mesoscale Thermal Variability in the Greenland Iceland Norwegian Sea, Saclatchen Memorandum (1988) No.SM-212.

[6] Levitus S., Climatological atlas of the world ocean, NOAA Prof. Pap. 13: 9-10. Natl. Oceanic and Atmos. Admin., Rockville, Md. (1982).

[7] Malanotte-Rizolli P., Hecht A., Large-scale properties of the eastern Mediterranean: A review, Oceanol. Acta 11 (1988) 323-335.

[8] Millot C., Circulation in the Western Mediterranean Sea, Oceanol. Acta 10, 2 (1987) 143-149.

[9] Morcos S.A., Sources of Mediterranean Intermediate Water in the Levantine Sea, in: Studies in Physical Oceanography: a Tribute to G. Wust on his $80^{\text {th }}$ Birthday (ed.) A.L. Gordon, 2 , Gordon and Breach, New York, 1972, 185-206.

[10] Ovchinnikov I.M., Foyad A.C., A study of the winter conditions of the Syrian waters in the eastern part of the Mediterranean Sea (in Russian), Okeanologia 34, 3 (1994) 467-471.

[11] Ovchinnikov I.M., Plakhin A., Moskalenko L.V., Neglyad K.V., Osadchiy A.S., Fedoseyev A.F., Krivoscheya V.G., Voytova K.V., Hydrology of the Mediterranean Sea, Gidrometeoizdat, Leningrad, 1976, p.37.

[12] Ovchinnikov I.M., The Formation of Intermediate Water in the Mediterranean, Oceanology 24, 2 (1984) 168-173.

[13] Ozsoy E., Hecht A., Unluata U., Circulation and Hydrography of the Levantine Basin, results of the POEM coordinated experiments 1985-1986, Prog. Oceanog. 22 (1989) 125-170.
[14] Ozsoy E., Hecht A., Unluata U., Brenner S., Oguz T., Bishop I., I atif M.A., Rozentramb Z., A Review of the Levantine Basin Circulation and its Variability during 1985-1988, Dyn. Atmos. Oceans 15 (1991) 421-456.

[15] Ozsoy E., Hecht A., Unluata U., Brenner S., Sur H.I., Bishop J., Latif M.A., Rozentraub Z., Oguz T., A synthesis of the Levantine Basin circulation and hydrography, 1985-1990, Deep-Sea Res. II, 40 (6) (1993) 1075-1193.

[16) POEM Group. General Circulation of the Eastern Mediterranean Sea, Earth Sci. Rev. 32 (1992) 285-309.

[17] Schlitzer R., Roether W., Oster H., Junghans H-G., Hausmann M., Mechelato A., Chlorofluoromethane and oxygen in the eastern Mediterranean, Deep-Sea Res. 38, 12 (1991) 15311551.

[18] Stanev E.V., Friedrich H. J. On the Assimilation of Climatological data by means of Numerical Circulation Models, examplified for the Mediterranean Sea, Oceanol. Acta 14, 2 (1991) 97-114.

[19] Sur H.I., Ozsoy E., Unluata U., Simultaneous deep and intermediate depth convection in the North Levantine Sea, winter 1992, Occanol. Acta 16, 1 (1993) 33-43.

[20] Theodorou A.J., The circulation of Levantine Intermediate Water in the northeastern Ionian Sea (late winter/early spring 1986), J. Mar. Syst. 1 (1991a) 359-372.

[21) Theodorou A.J., Some considerations on neutral surface analysis, Oceanol. Acta. 14, 3 (1991b) 205-222.

[22] Zodiatis G., Lens formation in the SE Ionian Sea and Double Diffusion, Ann. Geophys. 10 (1992) 935-942.

[23] Zodiatis G., Balopoulos E., Structure and Characteristics of Fronts in the North Aegean Sea, Boll. Oceanol. Teor. Appl. XI, 2 (1993) 113-124.

[24] Zodiatis G., Advection of the Black Sea Water in the North Aegean Sea, 'The Global Atm, and Ocean System, 2 (1994) $41-60$.

[25] Wust G. On the vertical circulation of the Mediterranean Sea, J. Geophys. Res. 66 (1961) 3261-3271. 